\title{
Preliminares para el estudio de las Decretales de la Biblioteca de la Real Colegiata de San Isi- doro de León ${ }^{1}$
}

\author{
Concepción Cosmen Alonso - Marta Elena Taranilla Antón
}

RESUMEN. El Códice XIV de la Biblioteca del Real Monasterio de San Isidoro de León, realizado en vitela finísima, contiene las Decretales de los Papas Gregorio IX (1227-1241) y Gregorio X (1271-1276).

El texto principal está escrito a dos columnas en el centro de la página y su letra gótica tiene particularidades propias de la cancillería papal de finales del siglo XIII; alrededor de aquél se colocan las glosas escritas también en letra gótica más pequeña. El aspecto general de la obra nos remite a un manual de Derecho eclesiástico propio de la Europa Mediterránea del citado siglo.

La decoración se puede ver en las iniciales que señalan las partes principales del texto, pero la iluminación se coloca únicamente en aquellas que inician el prólogo y los cuatro libros primeros..

Palabras clave: Códice, Decretales, glosas, iniciales, decoración, iluminación.

ABSTRACT. The Codex XIV made in parchment, held in the Real Colegiata de San Isidoro de León, contains the Decretales by Popes Gregory IX (1227-1241) and Gregory X (1271-1276).

The main text, arranged in two columns, is written in a gothic hand, showing some of the features of Papal Chancellery writings of late $13^{\text {th }}$ century, the surrounding gloss is in a smaller letter hand, gothic as well. Its appearance reminds us of a student book of Canon Law from Mediterranean Europe in that time.

The Decoration can be appreciated in the initials of the divisions of the major texts, and the Illumination in the prologue and in the frontispieces of book I through IV.

Key words: Codex, Decretales, gloss, initials, decoration, illumination.

En la biblioteca de San Isidoro de León se conserva el Códice XIV catalogado como Decretales de Gregorio IX que constituye un claro exponente de la miniatura gótica ${ }^{1}$. En el catálogo de códices y documentos de la colegiata isidoriana, realizado

-

${ }^{1}$ Este estudio se enmarca dentro del Proyecto I+D+I, referencia DHA 2001-0102, "La biblioteca de la Real Colegiata de san Isidoro de León", dirigido por la Prof. Dra. Fernández González. por J. Pérez Llamazares es considerado obra del siglo XIII' ${ }^{2}$.

-

${ }^{2}$ J. PÉREZ LlamaZARES, Catálogo de los códices y documentos de la Real Colegiata de San Isidoro de León, León, 1923, pp. 40-41. Esta misma clasificación y cronología la mantienen otros investigadores, véanse, M. GóMEZMoreno, Catálogo Monumental de España. Provincia de León, Madrid, 1925, p. 205. J. DomíngueZ BordONA, Manuscritos con Pinturas. Notas para un inventario de los conservados en colecciones públicas y particulares de España, t. I, Madrid, 1933, p. 186. A. VIÑAYO GONZÁLEZ, La 
El Códice XIV se compone de 326 folios que transmiten las Decretales de Gregorio IX (ff. 1 r.- 320 v.) y una parte de las Decretales de Gregorio X (ff. 321 r.- 326 v.) $)^{3}$. La obra jurídica citada en primer lugar se divide en cinco partes: Liber primus (ff. 1 r. 78 v.), Liber secundus (ff. 79 r. - 144 v.), Liber tertius (ff. 145 r. - 212 v.), Liber quartus (ff. 213 r. - 233 v.) y Liber quintus (ff. 234 r. - 320 v.). La foliación de cada uno de estos libros se realizó al minio y en números árabes dispuestos en el ángulo superior izquierdo del reverso de cada folio. Así, aunque por cuestiones prácticas hemos optado por una numeración correlativa a lo largo de todo el ejemplar, la foliación original es independiente para cada parte en la que se compartimenta dicha obra: Libro I (ff. 1 r. - 78 v.), Libro II (ff. 1 r. - 68 v.), Libro III (ff. 1 r. - 68 v.), Libro IV (ff. 1 r. - 21 v.) y Libro V (ff. 1 r. - 66 v.). La parte correspondiente a las Decretales de Gregorio X presentan una foliación actual a lápiz con errores en los números de folio, ya que éstos siguiendo una secuencia correlativa desde el inicio del manuscrito no concuerdan con el guarismo que les correspondería.

Los folios del ejemplar miden $245 \mathrm{x}$ $167 \mathrm{~mm}$., siendo, por lo tanto, su proporción o cociente entre anchura y altura de $0,68 \mathrm{~mm}^{4}$. El soporte del manuscrito es vitela. En cuanto al tipo de cuaderno el códice es bastante heterogéneo, organizándose sus folios en diecisiete octoniones, un septenión, dos quiniones, un cuaternión y un

Colegiata de San Isidoro de León, León, 1979, pp. 42-43 y A. VIÑAYO GONZÁLEZ, «El scriptorium medieval del monasterio de San Isidoro de León y sus conexiones europeas», Coloquio sobre la circulación de códices y escritos entre Europa y la Península en los siglos VIII-XIII, Santiago De Compostela, 1988, pp. 209-237.

${ }^{3}$ Respecto al número de folios se prescinde en su cómputo total de dos guardas volantes y dos guardas pegadas.

${ }^{4}$ Advertimos que éstas son las dimensiones medias, pudiendo existir mínimas variaciones a lo largo del manuscrito. bifolio. ${ }^{5}$ En todos los cuadernos se respeta la regla de Gregory, es decir, el vuelto de un folio y el recto del siguiente presentan la misma cara de la piel $^{6}$. Podemos reseñar que no se emplean los sistemas habituales de ordenación de fascículos por medio de signaturas y reclamos ${ }^{7}$.

Las páginas se configuraron para recibir texto a dos columnas resultando un cuadro de justificación para cada una de ellas delimitado externamente por doble vertical. La altura del cuadro de justificación es de $115 \mathrm{~mm}$. y su ancho de $35 \mathrm{~mm}$., midiendo el intercolumnio $0,5 \mathrm{~mm}$. Las rectrices horizontales parten de las perforaciones del margen de pliegue y se prolongan hasta las proximidades del corte ${ }^{8}$. Se utilizan para recibir escritura las 40 rectrices horizontales trazadas, incluidas las dispuestas en los espacios marginales destinadas a las glosas del texto base. En todos los folios el pautado se realizó con mina de

\footnotetext{
${ }^{5}$ Ofrecemos a continuación la relación de los fascículos que se corresponden con las diferentes tipologías halladas en el ejemplar objeto de atención. Los octoniones, cuadernos de 16 folios, son: (ff. 3-18; 19-34; 3550; 51-66; 67-82; 83-98; 99-114; 115-130; 145-160; 161176; 177-192; 193-208; 209-224; 225-240; 241-256; $257-$ 272; 273-288). El septenión, fascículo de 14 folios, es: (ff. 131-144). Los quiniones, fascículos constituidos por 10 folios, son: (ff. 289-298; 301-310). El cuaternión, cuaderno de ocho folios, es: (ff. 311-319). El bifolio es: (ff. 299-300). Sobre las diferentes estructuras que pueden adoptar los fascículos consúltese E. RUIZ, Manual de codicología, Madrid, 1988, pp. 120-123; J. LEMAIRE, Introduction à la codicología, Louvain-la-Neuve, 1989, pp. 57-58 y P. OSTOS, M. L. PARDO y E. E. RODRÍGUEZ, Vocabulario de Codicología (versión española revisada y aumentada del Vocabulaire codicologique de Denis Muzerelle), Madrid, 1997, pp. 97-98.

${ }^{6}$ Vid. L. GILISEN, Prolégomènes à la Codicologie, Gand, 1977, pp. 14-20; E. RUIZ, Manual de..., pp. 129130 y P. Ostos, M. L. PARDO y E. E. RODRíGUEZ, Vocabulario de Codicología..., p. 98.

${ }^{7}$ Estos elementos, cuya función es asegurar la correcta sucesión de los cuadernos en un ejemplar manuscrito, son estudiados por E. RUIZ, Manual de..., pp. 163-165 y P. OSTOS, M. L. PARDO y E. E. RODRÍGUEZ, Vocabulario de Codicología..., pp. 99-100 y p. 110.

${ }^{8}$ Muchos de estos orificios no son perceptibles.
} 
plomo y la escritura con tinta negra de tonalidad intensa.

Encuadrando el texto principal y utilizándose el mismo pautado se ubican, cubriendo toda la superficie marginal, las glosas realizadas en tinta parda. Por otra parte, y, con menos frecuencia, se usa la tinta roja para los epígrafes temáticos, para las mayúsculas caligráficas intercaladas en el texto y para los números de libro y su foliación. Por último, el color azul está presente en capitales decoradas.

La escritura adoptada en este códice es letra gótica libraria redonda de la segunda mitad del siglo XIII para el texto base, muy parecida a la que se empleaba en la cancillería pontificia a finales de la citada centuria, cuando ocupaba la silla de San Pedro Bonifacio VIII (1294-1303), y letra gótica libraria intermedia, entre redonda $\mathrm{y}$ cursiva, para las glosas ${ }^{9}$. Esta última destaca por su módulo reducido y la tinta pálida con la que se trazó, mientras que la primera presenta un módulo mayor y más intensidad en la tintura.

Varias manos participan en la materialización del texto base, circunstancia que provoca la existencia de tres morfologías gráficas diferentes. El artífice principal, al que llamamos escribano A, copió los ff. $1 \mathrm{r}$. - 299 r. La segunda intervención, atribuible al calígrafo B, comprende los ff. 299 v. - 320 v. Un tercer amanuense, C, realizó los ff. 321 r. - 326 v. Por último, un cuarto copista, $\mathrm{D}$, se encargó de la factura de las glosas.

Debido al empleo del códice como libro de texto, su ornamentación es muy escasa y se circunscribe únicamente a seis escenas miniadas insertas en otras tantas iniciales dispuestas siempre en la página

\footnotetext{
${ }^{9}$ Tenemos que agradecer al doctor Santiago Domínguez sus clarificadoras observaciones respecto a la letra del Códice XIV.
}

inicial de los libros en los que se subdivide la obra: G (f. 1 r.), R (f. 1 r.), F (f. 1 r.), D (f. 79 r.), U (f. 145 r.) y D (f. 213 r.). La totalidad de estos trabajos artísticos son obra de un mismo iluminador, cuya personalidad es anónima.

La encuadernación está formada por dos planos de madera forrados de piel en color marrón oscuro y conserva dos cierres de cuero deteriorados. La decoración repujada, de clara filiación mudéjar, de la tapa anterior se dispone en una orla externa compuesta por una decoración de lazo que origina formas hexagonales alargadas, cuyo espacio interior se cubre a su vez con motivos de ochos enlazados. Los bordes interno y externo de la misma se ornan con un tema de cableado. El tapiz central se decora con motivos de rombos y círculos con botón interior. En el ángulo superior derecho se localiza una etiqueta identificativa del ejemplar, en la que se registra el número del códice, su título y cronología. La ornamentación de la tapa posterior presenta el mismo esquema decorativo, pero el interior de los hexágonos de la orla contiene formas romboidales con temas vegetales que recuerdan el motivo de la flor de lis. Respecto al tapiz central en este caso la ornamentación es menos profusa, configurando únicamente un enmarque rectangular. El lomo, compuesto por cuatro nervios y cinco entrenervios, está muy deteriorado, faltando sus dos entrenervios superiores. Su decoración consiste en una trama romboidal, apareciendo pintado con tinta blanca y números árabes, en el cuarto entrenervio, el número de su catalogación. Con casi toda probabilidad podemos afirmar que es muy posible que la encuadernación sea coetánea al códice ${ }^{10}$, puesto que sus esquemas decorativos de raigambre mudéjar ya estaban plenamente articulados en el siglo XIII.

\footnotetext{
${ }^{10}$ M. LÓPEZ SERRANO, La encuadernación española: breve historia, Madrid, 1972, pp. 42-49.
} 
Las Decretales de Gregorio IX (12271241) son una obra de compilación del derecho canónico que el citado Papa encargó al jurista Raimundo de Peñafort en 1230. En ella se recogió y organizó, abreviadamente, todo el material jurídico usado por la Iglesia dando lugar a un cuerpo de doctrina unitario. El texto se dividió en cinco libros, a la manera del Código de Justiniano, iudex, iudicium, clerus, connubia y crimen, como era común en la Edad Media, y fue aprobado por la bula pontificia Rex pacificus el 5 de septiembre de $1234^{11}$.

Las Decretales fueron enviadas por el pontífice a las universidades de Bolonia, París y Salamanca con el fin de ser utilizadas como libros de texto.

De acuerdo con todo lo anterior, el libro I versa sobre las Fuentes del Derecho, la organización judicial, la paz y la tregua (ff. 1 r. - 78 v., del ejemplar que estamos estudiando); el libro II se refiere al Derecho Procesal (ff. 79 r. - 144 v.); el libro III trata del clero y los bienes eclesiásticos (145 r. 212 v.); el libro IV se centra en el matrimonio, esponsales y filiación (213 r. - 233 v.), y, por último, el libro $\mathrm{V}$ alude a los delitos $\mathrm{y}$ penas (234 r. - 320 v.).

En los espacios marginales de cada folio se disponen profusas glosas, tal como era común en estos textos jurídicos medievales, en las que juristas y maestros de universidades incluían sus comentarios analizando la doctrina original ${ }^{12}$. El más conocido glosista de estas Decretales fue Bernardus de Botone Parmensis ${ }^{13}$.

\footnotetext{
${ }^{11}$ L. Miguélez, S. AlONSO y M. CABreros, Código de Derecho Canónico y Legislación complementaria, Madrid, 1954, p. XXI.

12 J. T. MARTín DE AGAR, Introducción al Derecho Canónico, Madrid, 2001, p. 23.

${ }^{13}$ Illuminating The Law. Medieval Legal Manuscripts in Cambridge Collections, London/Turnhout, 2001, p. 19.
}

El Códice XIV, en su parte final, contiene las Decretales de Gregorio X (ff. 321 r. 326 v.), quien ocupó la silla apostólica entre 1271 y 1276. Su obra jurídica será recopilada por el Papa Bonifacio VIII (1294-1303) en el llamado Liber sextus, que recoge las disposiciones legislativas desde 1234 a $1282^{14}$.

${ }^{14}$ Ibidem, p. 22. A continuación reseñamos el contenido detallado del códice, que puede sintetizarse así:

\section{DECRETALES DE GREGORIO IX Libro I}

F. 1 r.: De fide catholica et suma trinitate. En el f. 3 r.: De constitutionibus. En el f. 5 r.: De rescriptis. En el f. 13 v.: De consuetudine. En el f. 15 v.: De postulatione. En el f. 19 v.: De electione et electio potestate. En el f. 35 r.: De translatione. En el f. 36 v.: De aucte et usu pallii. En el f. 37 v.: De renunciatione. En el f. 41 v.: De suplenda negligentia prelatorum sub die. En el f. 42 r.: De temporibus et ordinationum vel qualitate ordinandorum. En el f. 44 r.: De scrutinio in ordine faciendo. En el f. 44 r.: De ordinatis ab excomunicatio vel eo qui resignavit. En el f. 44 v.: De qualitate et etater et ordinatione prificiendorum. En el f. 46 v.: De sacra unctione. En el f. 48 r.: De sacramentis itinerandis vel non. En el f. 48 v.: De filiis presbitorum ordinandis vel non. En el f. 50 r.: De servis non ordinandis et eorum manumissione. En el f. 50 v.: De obligatis ad roncima ordinandi vel non. En el f. 50 v.: De corpe viciatis ordinandis vel non. En el f. 51 v.: De bigamus non ordinandis. En el f. 52 r.: De clericis peregrinis. En el f. 52 v.: De officio in archidiaconis. En el f. 53 v.: De officio archipresbiteri. En el f. 54 r.: De officio primicerii. En el f. 54 v.: De officio sacriste. En el f. 54 v.: De officio custodis. En el f. 54 v.: De officio vicarii. En el f. 55 r.: De officio et potestate iudicis delegatis. En el f. 63 r.: De officio legati. En el f. 64 r.: De officio iudicis ordinatis. En el f. 67 v.: De maioritate et obedientia. En el f. 69 v.: De treuga et pace. En el f. 70 r.: De pactis. En el f. 70 v.: De transactionibus. En el f. 71 v.: De postulando. En el f. 72 r.: De procuratorum. En el f. 73 v.: De syndico. En el f. 74 v.: De integrum restitutione. En el f. 76 v.: De alienatione iudicii mutandi [...]. En el f. 77 r.: De arbitris.

$$
\text { Libro II }
$$

En el f. 79 r.: De iudiciis. En el f. 81 v.: De foro conpetenti. En el f. 84 r.: De libelli oblatione. En el f. 84 r.: De mutuis petitoribus. En el f. 84 v.: De litis contestatione ut lite non contestatione. En el f. 86 r.: De iuramento calumpnie. En el f. 87 r.: De dilationibus. En el f. 87 v.: De feriis. En el 88 r.: De ordine cognicionum. En el f. 89 r.: De [...] petitionibus. En el f. 89 v.: De ca [...] possesionis et propietatis. En el f. 90 v.: De restitucione spoliatorum. En el f. 94 v.: De dolo et contumat. En el f. 96 v.: De eo qui mititur in posesionem causa rei servande. En el f. 98 r.: De sequestratione possitionum et fructum. En el f. 98 v.: De probatori- 
bus. En el f. 102 r.: De testibus et atestacionibus. En el f. 109 v.: De testibus cogendis vel non. En el f. 110 v.: De fide instrumentorum. En el f. 113 v.: De presumptionibus. En el f. 115 r.: De iure iurando. En el f. 121 v.: De exceptionibus. En el f. 124 r.: De prescriptionibus. En el f. 127 r.: De sententia et re iudicata. En el f. 131 r.: De apellationibus, recusationibus et relacionibus. En el f. 143 v.: De peregrinationibus. En el f. 143 v.: De confirmatione utilis vel inutilis.

\section{Libro III}

En el f. 145 r.: De vita et honestate clericorum. En el f. 146 v.: De cohibitatione clericorum et mulierum. En el f. 147 v.: De clericis coniugatis. En el f. 148 v.: De clericis non residentibus in ecclesia vel prebenda. En el f. 150 r.: De prebendis et dignitatis. En el f. 155 v.: De clerico delibilitato vel egrotante. En el f. 156 r.: De institutionibus. En el f. $157 \mathrm{r} .:$ De concessione prebende vel ecclesie non vacante. En el f. 160 r.: Ne sede vacante aliquid innovetur. En el f. 160 v.: De hiis que fuit aprelato sine consensu capituli. En el f. 162 r.: De hiis que fiunt a maiore parte capituli. En el f. 163 r.: De ecclesiastica beneficia sine diminutione conferuntur. En el f. 163 v.: De rebus ecclesie non alienandis. En el f. 165 r.: De precariis. En el f. 165 r.: De commodato. En el f. 165 r.: De deposito. En el f. 165 v.: De [...] et venditione. En el f. 166 v.: De locato et conducto. En el f. 167 r.: De rerum permutatione. En el f. 168 r.: De feudis. En el f. 168 v.: De pignoribus et aliis e cancionibus. En el f. 169 v.: De fidevissoribus. En el f. 170 v.: De solutionibus. En el f. 170 v.: De donationibus. En el f. 172 v.: De peculio clericorum. En el f. 172 v.: De testamentis et ultimis voluntatis. En el f. 177 r.: De sucessionibus ab intestato. En el f. 177 v.: De sepulturis. En el f. 179 v.: De parochiis et alienis parochiis. En el f. 179 v.: De decimus primiciis et oblationibus. En el f. 183 v.: De regularibus et transeuntibus ad religionem. En el f. 186 v.: De conversione coniugatorum. En el f. 189 v.: De conversione infidelium. En el f. 189 v.: De voto et voti redemptione. En el f. 192 r.: De statu monachorum et canonicorum regularium. En el f. 195 r.: De religiosis domibus ut episcopis sit subiter. En el f. 196 r.: De capellanis monachorum et aliorum religiosorum. En el f. 196 v.: De iure patronatus. En el f. 199 v.: De censibus exaccionibus et procuracionibus. En el f. 202 v.: De consecratione ecclesie vel altaris. En el f. 203 r.: De celebratione missarum et sacramento eucharistie et divinus officiis. En el f. 206 v.: De baptismo et eius effectu. En el f. 208 v.: De presbitero non baptistato. En el f. 209 r.: De custodia eucharistie crismatis et aliorum sacrorum. En el f. 209 r.: De reliquis et veneratione sacrorum. En el f. 209 v.: De observancia ieuniorum. En el f. 210 r.: De purificatione post partum. En el f. 210 r.: De ecclesiis edificandis. En el f. 210 v.: De inmunitate ecclesiarum et rerum ad eas pertenencium. En el f. 211 v.: De clerici et monachi scolaribus negociis se inmisceant.

\section{Libro IIII}

En el f. 213 r.: De sponsalibus et matrimonio. En el f. 216 v.: De desponsatione in puberum. En el f. 218 r.: De clandestina desponsatione. En el f. 218 v.: De sponsa duo-
La iluminación del códice está constituida por seis iniciales historiadas en las que se representan hechos vinculados di-

rum. En el f. 219 r.: De conditionibus appositis in desponsatione vel aliis contractibus. En el f. 220 r.: A de clerici vel voventes in possuit. En el f. 221 r.: De eo qui duxit in uxore quam polluit per ad ulterum. En el f. 221 v.: De coniugio leprosorum. En el f. 222 r.: De coniugio servorum. En el f. 222 v.: De natis ex libero venere. En el f. 222 v.: De cognitatione spirituali. En el f. 223 v.: De cognotatione legali. De eo qui cognovit consanguineam uxoris sue. En el f. 224 v.: De consaguinitate et affinitate. En el f. 226 r.: De frigidis et maleficiatis et impotencia coenudi. En el f. 227 v.: De matrimonio contracto contra interdictum ecclesie. En el $\mathrm{f}$. 228 r.: Qui filii sunt legittimi. En el f. 231 r.: Qui [...] accusare possunt. En el f. 231 v.: De divorciis. En el f. 233 v.: De donationibus vit iure et uxorem et de dote pro divorium dare.

\section{Libro $V$}

En el f. 234 r.: De denuntiationibus. En el f. 235 r.: De acusationibus. En el f. 238 v.: De calumpnacionibus. En el f. 239 r.: De symonia et ne aliquid exigatur et permutat pro spiritualibus laudibus. En el f. 246 r.: De magisterio ne aliquid exigant pro licencia docendi. En el f. 247 r.: De iudeis et sarracenis et eorum servis. En el f. 250 r.: De hereticis. En el f. 253 r.: De scismaticis. En el f. 253 v.: De apostatis et itinerandis baptismum. En el f. 254 r.: De hiis qui filios occidunt. En el f. 254 r.: De infantibus languidis expositis. En el f. 254 r.: De homicidio voluntario vel casualis. En el f. 258 r.: De clericis pugnantibus in duello. En el f. 258 r.: De sagitariis. En el f. 258 r.: De torneamentis. En el f. 258 v.: De adultus et stupro. En el f. 259 v.: De raptoribus incendiariis et molatoribus ecclesiarum. En el f. 260 r.: De furtis. En el f. 260 v.: De usuris. En el f. 262 r.: De crimine falsi. En el f. 263 v.: De sortilegiis. En el f. 264 r.: De collusione. En el f. 264 v.: De delicto puerorum. En el f. 264 v.: De clerico venatore. En el f. 264 v.: De clerico percussore. En el f. 265 r.: De maledicis. En el f. 265 r.: De clerico excomunicato deposito vel interdicto mistrante. En el f. 266 v.: De non ordinato mistrante. En el f. 266 v.: De clerico per saltum pronoto. En el f. 267 r.: De eo qui furtive ordinem suscepit. En el f. 267 r.: De excesibus prelatorum et subditorum. En el f. 270 v.: De novi operis nunciatone. En el f. 271 v.: De privilegiis et excesibus privilegiatorum. En el f. 277 r.: De purgatione canonica. En el f. 280 r.: De purgatione vulgari. En el f. 280 r.: De iniuriis et dampno dato. En el f. 280 v.: De peniis. En el f. 282 r.: De peniis et remissionibus. En el f. 284 v.: De sententia excumunitionis. En el f. 294 r.: De verborum significatione. En el f. 299 r.: De regulus iuris. En el f. 300 r.: De cestus et acc[...]. En el f. 300 v.: De sententia et re iudica. En el f. 304 v.: De rob[...] et alienandis. En el f. 304 v.: De privilegiis. En el f. 305 r.: De sententia excomunicationis.

DECRETALES DE GREGORIO X

Desde el f. 321r. al 326v.: De electione et electi. 
rectamente con el contenido del texto. Dichas imágenes se colocan al inicio de la obra y de los diversos libros que la componen, con el fin de ilustrar el origen de la misma, la bula que la hizo pública y algunos de los asuntos que en ella se desarrollan ${ }^{15}$. Como es habitual, el comienzo de cada libro va ilustrado, a excepción del último, el liber quintus, que no lleva imagen alguna.

\section{LETRA G (f. 1 r.)}

La inicial situada al comienzo del Libro I ( $350 \times 260 \mathrm{~mm}$.), encierra el retrato del Papa Gregorio IX sentado, con mitra, vestido con túnica blanca y casulla de tono vináceo. El almohadón del asiento, el escabel, el tocado y el remate de la vestimenta son aureos. Le acompañan dos clérigos tonsurados con túnica blanca y manto gris, posiblemente dos dominicos, Raimundo de Peñafort y un colaborador, ya que al primero le fue encargada la compilación, que entrega en forma de libro encuadernado en rojo al Sumo Pontífice. Este conjunto se dispone sobre un fondo de color azul salpicado en toda su superficie por asociaciones triangulares de puntos simples en tinta blanca. El tema representado encuentra justificación tanto en el texto que acompaña (Gregorius episcopus...) como en el contenido del libro de las Decretales en el que se encuadra, ya que Gregorio IX fue su promotor (Ilust. 1).

El ductus de la capital, en color azul y rojizo, en su remate curvo inferior, está delimitado por dos trazos negros, que en el extremo superior se prolongan fuera del enmarque en forma de voluta. Además, en los extremos curvos laterales, más anchos,

\footnotetext{
${ }^{15}$ Las imágenes que encontramos en este Códice XIV son, en general, las que se emplean con más asiduidad en la decoración de este tipo de textos jurídicos en los siglos XIII y XIV, véase, Illuminating The Law..., pp. 82-97.
}

aparecen formas de palmetas. El cuerpo se superpone a un fondo de estructura cuadrangular bordeado por un enmarque verde entre dos líneas negras; en los ángulos del mismo aparecen cuatro puntos dorados bordeados por palmetas blancas sobre un fondo vináceo; adyacente al marco de la letra. Por último, en su flanco derecho, se realizó un recuadro de enmarque rojo que alberga la inscripción alusiva al Papa.

Fuera del marco y alrededor de la voluta del remate superior de la letra se constituye una forma triangular con contorno negro. En su interior tres motivos curvos se dirigen a ocupar los ángulos mientras que la zona central está ocupada por tres botones dorados. Sobre el trazo superior del enmarque se pintó un perro perfilado en negro y coloreado en tono beige.

\section{LETRA R (f. 1 r.)}

La capital ubicada debajo de la anterior al comienzo del Libro I ( $150 \times 150 \mathrm{~mm}$.), contiene el retrato de un soberano sentado en su trono, vestido con túnica grisácea y manto azul forrado de piel. El monarca está coronado y porta cetro en la mano derecha. La corona y el cojín fueron dorados. La figura del rey se superpone a un fondo vináceo ornado con asociaciones triangulares formadas por tres puntos blancos simples. Esta figura alude directamente al texto que inicia (Rex Pacificus...), la bula pontificia por la que se aprobó este conjunto de normas jurídicas como ya hemos apuntado en líneas precedentes (Ilust. 2).

La letra se coloca sobre una superficie cuadrangular azul fracturada en su parte superior izquierda en un ángulo recto. El ductus de la letra está delimitado por dos líneas negras que en los trazos curvos reciben motivos foliáceos y en el tramo recto una sucesión de círculos blancos. El bucle superior de la letra se remata en voluta que termina en una pequeña esfera y el marco inferior vuelve a repetir el motivo. A partir 
de estos remates se diseñan, en verde y caldera, otras formas alargadas que se prolongan en el margen de pliegue de la primera columna del texto principal.

\section{LETRA F (f. 1 r.)}

En la segunda columna del texto, del mismo Libro I, la letra $(370 \times 230 \mathrm{~mm})$ origina un espacio cuadrangular en el que se representan dos figuras nimbadas, vestidas con túnica gris y manto azul, sentadas y con sendos libros en sus manos. Entre las cabezas de ambas se representó descendiendo la paloma del Espíritu Santo con halo de santidad. Los personajes se sientan en un banco corrido en cuyo cuerpo se señalan tres huecos a modo de saetera. Los nimbos y el almohadón del asiento son dorados. El fondo de la composición es vináceo y se decora con las ya mencionadas asociaciones de tres puntos blancos. El enmarque está formado por dos líneas negras relleno de tono rojizo en la parte superior e inferior, mientras que en el lado derecho se hace en color verde y en posición adyacente otro enmarque idéntico, pero en color bermejo encuadra la palabra firmiter. La escena representa las tres figuras de la Santísima Trinidad, una composición muy común en la miniatura medieval occidental fuera de Italia ${ }^{16}$. Este tema se encuentra en plena conexión con el texto que acompaña ${ }^{17}$. La

-

${ }^{16}$ Illumination The Law..., p. 94 . Un ejemplar de Decretales, del siglo XIII, conservado en la biblioteca de la catedral de Hereford (England), posee en su folio inicial dos imágenes miniadas muy parecidas a las que acabamos de referirnos, las cuales, van unidas también a las iniciales G de Gregorius y F de Firmiter. En la primera, al Papa recibe el texto de un dominico y en la segunda se representa a la Trinidad por medio de dos figuras sentadas y sobre ellas la paloma del Espíritu Santo.

${ }^{17}$ FF. 1 r. - 1 v.: "Firmiter credimus et simplicit et fitemur que unus solus est verus deus eternis mansus et inconmutabilis omnipotens incomprehensibilis et ineffabilus pater et filius et spes tres quidus persone summa essencia substancia seu natura simplex omnio pater filius a patre solo ac spiritus santus...". imagen trinitaria pintada corresponde al tipo denominado por Germán de Pamplona "Padre e Hijo entronizados con la paloma volando", modelo que empieza a representarse en el siglo XII en la miniatura anglosajona, en el XIII en la francesa y alemana, y a principios de la decimocuarta centuria en los códices iluminados hispanos ${ }^{18}$. Como es habitual en este tipo trinitario, las dos primeras personas son idénticas, el Padre y el Hijo tienen las mismas vestimentas, portan los mismos atributos y se muestran la misma actitud (Ilust 3).

\section{LETRA D (f. 78 r.)}

En este caso la inicial se corresponde con el comienzo del Libro II $(360 \times 220$ $\mathrm{mm}$.), De iudiciis. En el campo interior de la mayúscula se representa un conjunto formado por un clérigo ataviado con túnica gris y manto marrón acompañado por dos personajes laicos, vestidos el de derecha con túnica azul y el de la izquierda con un vestido en oro. Al igual que ocurría con las otras letras, el fondo es azul y se encuentra decorado con asociaciones triangulares constituidas por tres puntos blancos. (Ilust 4).

\section{LETRA U (f. 145 r.)}

Dentro del Libro III esta inicial (390 x $240 \mathrm{~mm}$.) corresponde a la frase "ut laici" y se encuentra en el capítulo dedicado a la vida y honestidad de los clérigos. La inicial representa a un obispo sedente sobre un banco con cojín aleccionando a dos personajes. El fondo de la composición es de tono vináceo ornado con puntos blancos que forman triángulos equiláteros. El prelado viste túnica blanca bajo una casulla azul y

${ }^{18}$ G. DE PAMPLONA, Iconografía de la Santísima Trinidad en el arte medieval español, Madrid, 1970, pp. 159160; J. F. ESTEBAN LORENTE, Tratado de iconografia, Madrid, 1994, p. 210 y L. RÉAU, Iconografía del Arte Cristiano. Iconografía de la Biblia - Antiguo Testamento, T. 1/Vol. 1, p. 46. 
porta en su cabeza una mitra con orla dorada. Los fieles visten sobretúnicas con capucha, uno en verde y otro en azul y en sus cabezas se destaca la tonsura. La posición de los brazos y manos del mitrado y una de las figuras nos señalan gestos de conversación y la posición de los pies calzados rompe el marco de la letra. (Ilust. 5).

\section{LETRA D (f. 213 r.)}

El tema de la inicial $(360 \times 260 \mathrm{~mm}$.) conecta convenientemente con el capítulo del Libro IIII de estas Decretales que lleva por título "De sponsalibus et matrimonio". Pero, además, la inicial con el texto adyacente forman la frase "De Francia". En el centro de la composición se representa a un sacerdote flanqueado a la izquierda por una mujer, vestida con túnica gris ceñida por un cinturón, y la derecha por un hombre, con túnica roja y sobretúnica grisácea, en el momento de su desposorio. El sacerdote porta túnica blanca y casulla roja, su cabeza está tonsurada, delante de sus pies se representa un escabel dorado y con sus manos sujeta unidas las de los contrayentes, al mismo tiempo que mira hacia la dama. El fondo de la composición es azul con puntos blancos agrupados formando triángulos (Ilust. 6).

Atendiendo a los aspectos bibliográficos, paleográficos, estilísticos e iconográficos expuestos estamos en condiciones de proponer como cronología aproximada para la realización del códice los años finales del siglo XIII, sin poder por el momento aclarar cuestiones relativas al origen y filiación estilística del manuscrito. No obstante, nos apoyamos en que la obra de Gregorio $X$ se aprobó con posterioridad a 1276, que la escritura data de finales de la decimotercera centuria y que la imagen trinitaria, representada en una de las miniaturas, corresponde a un modelo foráneo que no penetró en el ámbito peninsular hasta momentos cercanos al siglo XIV. 


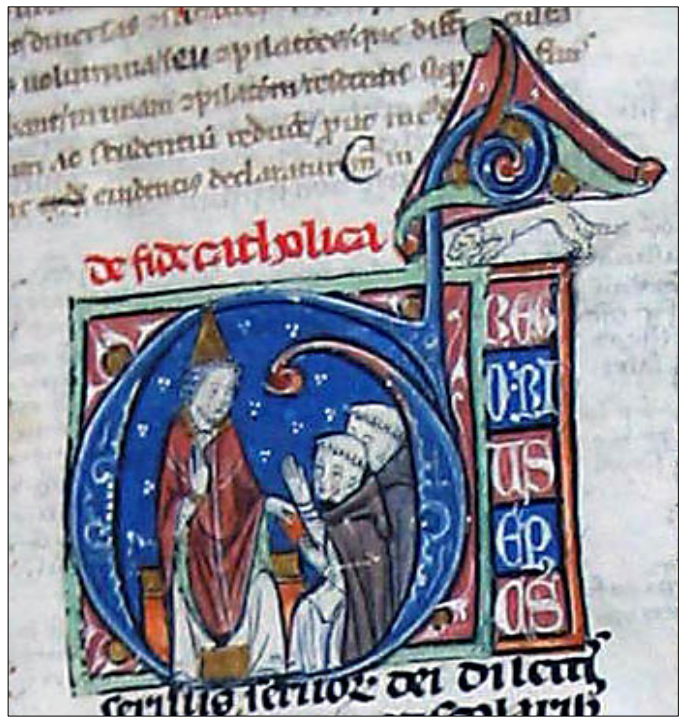

- Ilus. 1 -F. 1r. Letra G. El Papa Gregorio IX

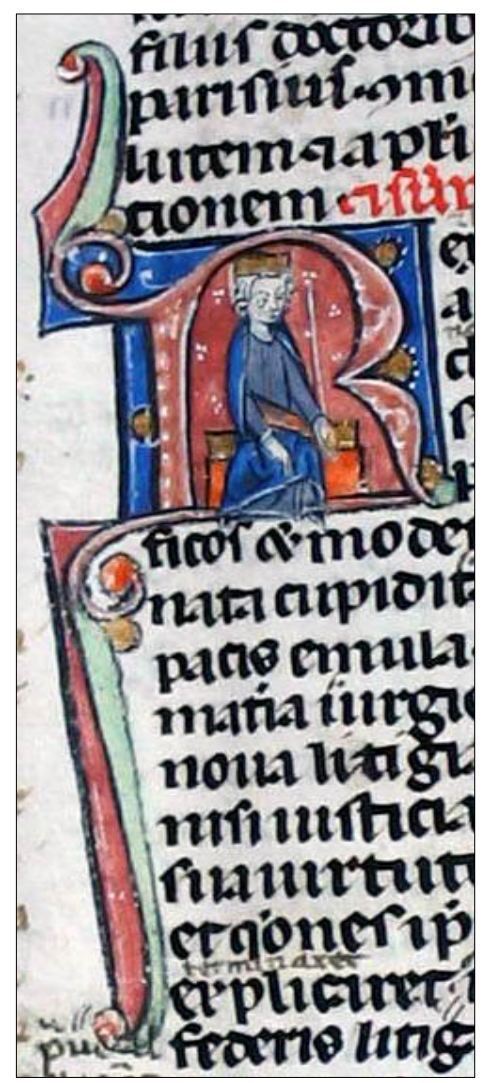

- Ilus. 2 -F. 1r. Letra R. Imagen de un rey

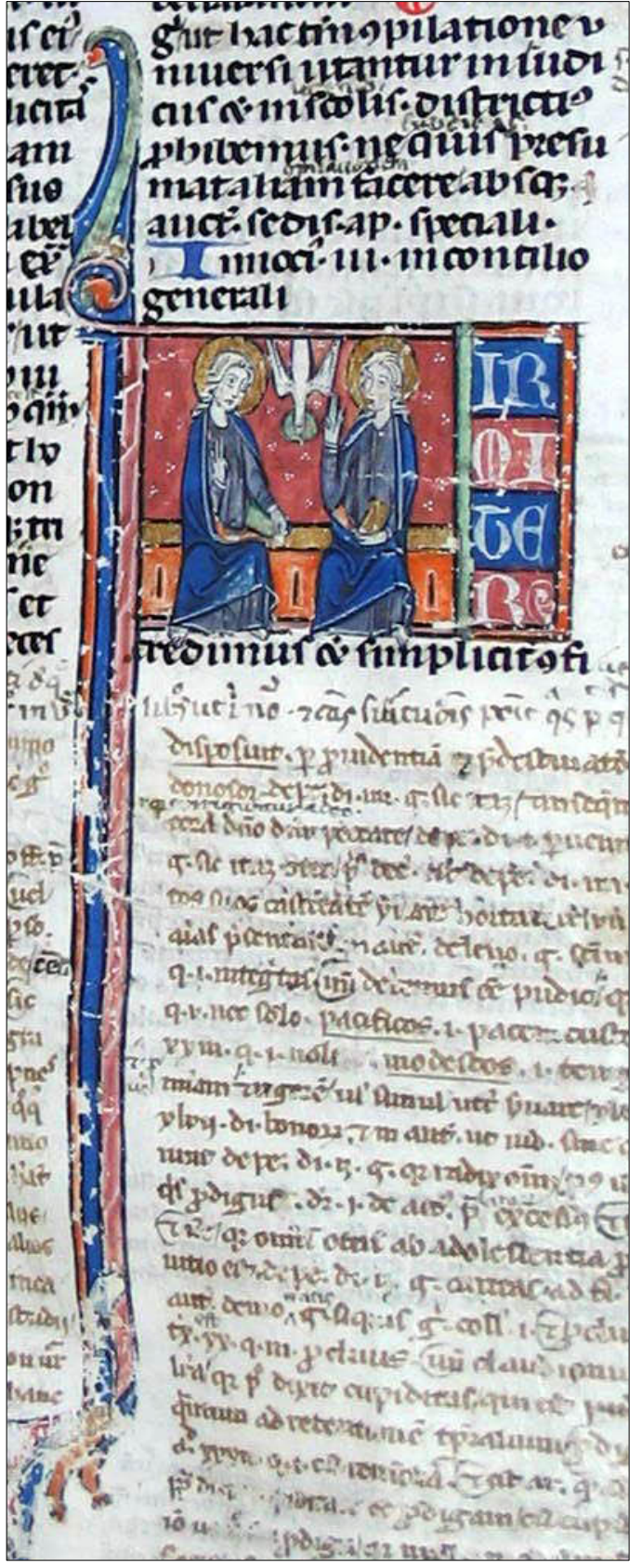

- Ilus. 3 -F. 1r. Letra F. La Trinidad 


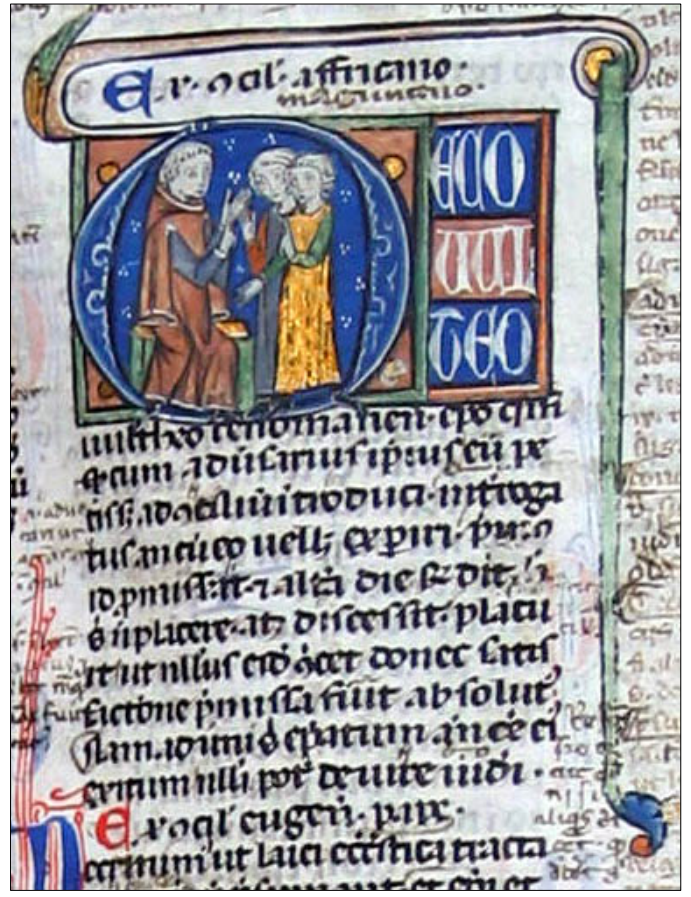

- Ilus. 4. F. 78r. Letra D. Clérigo y dos laicos

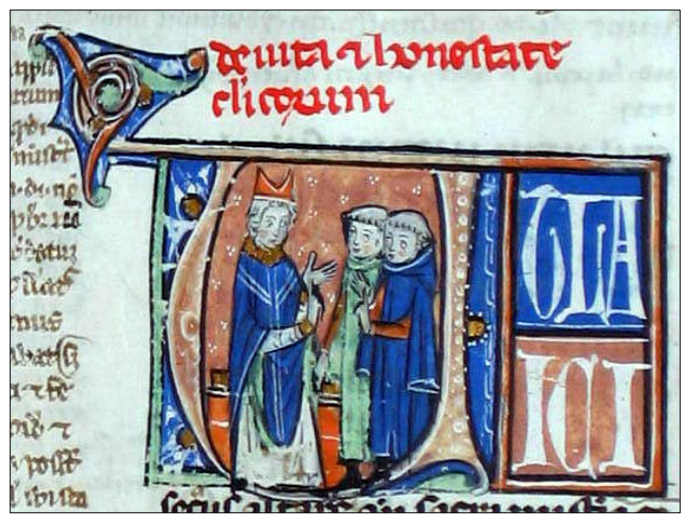

- Ilus. 5. F. 145r. Letra U. Obispo y clérigos

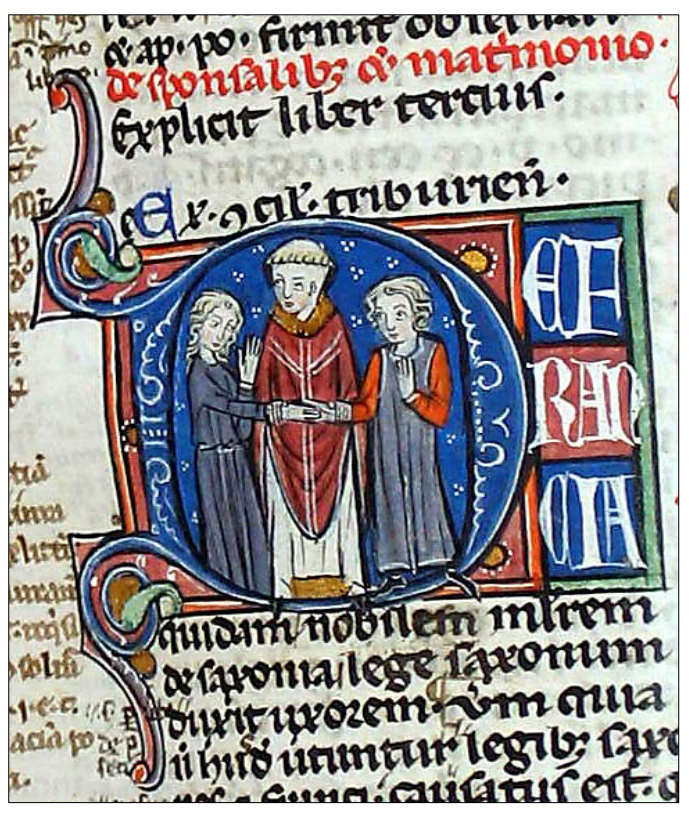

- Ilus. 6. F. 213r. Letra D. Esponsales 